\title{
The New Public Health Hegemony: Response to Severe Acute Respiratory Syndrome (SARS) in Toronto
}

\author{
SARAH SANFORD \& S HARRIS ALI
}

York University, Canada. E-mail: sarahs@yorku.ca

\begin{abstract}
The 2003 Severe Acute Respiratory Syndrome (SARS) outbreak presented a challenging period for public health in Toronto. Many old and new public health measures were implemented at local, national and global levels, in an attempt to control the outbreak of the disease. Among these, surveillance mechanisms dominated, which involved new epidemiological techniques and statistical profiling strategies. In this paper, Gramsci's concept of hegemony is used to further understandings of public health governance during the outbreak of emerging infectious diseases. Specifically, the function of the discourse of 'risk' in public health governance is examined, along with public health as a 'moral agent' in the naturalization of specific public health measures. In addition, the pervasive discourse of 'security' is discussed in relation to current public health practices. These characteristics of public health are examined with consideration of their potential for propagating social exclusion and stigmatization of individuals and communities. The specific case of SARS in Toronto is used to examine the implications of public health as a mechanism for social control and reproduction rather than the promotion of equality in health throughout the population.
\end{abstract}

Social Theory \& Health (2005) 3, 105-125. doi:10.1057/palgrave.sth.8700048

Keywords: hegemony; surveillance; risk; morality; security; SARS

\section{BACKGROUND: THE SARS OUTBREAK IN TORONTO}

In late February 2003, a physician from the Guangdong Province in China who had treated patients with an unclassified form of atypical pneumonia stayed at the Metropole Hotel in Hong Kong to attend a nephew's wedding. The physician himself became ill and during his visit, 12 guests of the hotel became infected with the disease later to be identified as SARS; however, these guests continued their travel to various locations, including: Singapore, 
Hanoi, Toronto, and other areas of Hong Kong. One 78-year-old Canadian woman was among these, and following the return to her Toronto home, her 44-year-old son also became ill and subsequently visited local hospitals for treatment. On 5 March 2003, the woman died and her son passed away two days later. During their hospital stay, many patients and staff were unknowingly exposed to the severe acute respiratory syndrome (SARS) virus through various pathways (Naylor et al., 2003). The first case of SARS was reported to Toronto Public Health on 9 March 2003 as a possible case of tuberculosis. Toronto Public Health held a press conference on 14 March 2003 and activated its emergency response plan. A week and a half later, the province of Ontario pronounced an unprecedented provincial health emergency, where 13,374 people were placed in quarantine for the first time in 50 years (Basrur et al., 2004).

A month later, on 12 April 2003, a cluster of SARS cases was identified in a close-knit religious community. The exposure for these cases was traced back to mid-March at which time several members of a large extended family had visited the Toronto-area hospital that was the initial outbreak epicentre (Naylor et al., 2003). Within one month of the index case, there were in total: 13 SARS-related deaths, 97 probable cases, and 1,137 suspected cases in the Toronto area. By the following month, the total number of cases appeared to reach a plateau and on May 16, 2003 an official announcement was made that SARS had been defeated in this city (Naylor et al., 2003). One week later, however, a second wave of SARS patients appeared in a Toronto-area hospital as five patients were quarantined; this second outbreak was referred to as SARS II (Naylor et al., 2003). Approximately 700 Toronto Public Health staff worked in some capacity relating to the SARS response between mid-March and the end of June, when Canada was removed from the World Health Organization's list of SARS-affected countries (Basrur et al., 2004).

Shortly after the SARS outbreak in Toronto was officially declared to have ended, several independent inquiries were established to investigate different aspects of the outbreak, including the National Advisory Committee on SARS and Public Health (NACSPH) established by the federal government. The NACSPH and subsequent reports have discussed some of the outcomes of the SARS outbreak. While these documents generally called for the strengthening of public health through the expansion of investment in existing programs (e.g. the extension of surveillance technologies), they tended to be less critical of the potential for state institutions (e.g. those in the public health sector) to contribute to discriminatory outcomes, such as the social exclusion experienced by Asian communities in Toronto, and the members of a number of healthcare professions, especially nursing. The recommendations to increase efficiency and expand public health responses to infectious 
disease may offer some limited insight into the weaknesses of public health in its existing state; however, the approach neglects to consider the potential contribution of public health in the manufacturing of such exclusionary effects.

In this light, we seek to expand understandings of social and economic inequality by addressing the potential role of state institutions, specifically public health, in the perpetuation of such disparities in current society through the use of Antonio Gramsci's (1971) concept of hegemony. This theoretical analysis of public health is supplemented by empirical research concerning the Canadian experience of SARS in 2003. The data were collected principally from the federal report published by the NACSPH (Naylor et al., 2003) but were also drawn from reports prepared by the Ontario Expert Panel on SARS and Infectious Disease Control (Walker et al., 2003) and a second provincial committee referred to as the SARS Commission (Campbell, 2004). In addition, the analysis was supplemented with data from local and national newspaper articles focusing on the SARS outbreak. On this basis, we argue that (through the specific context of the SARS outbreak) the current composition of public health establishes an institutional backdrop in which processes of differentiation (and subsequently marginalization) can occur. Central to this analysis is the proposal that the institution of public health has the potential to function as a hegemonic structure within current society. The sections within this paper thus comprise a framework for the new public health hegemony, with surveillance, risk, morality and security as components governing public health that contribute to social reproduction within capitalism. We begin by reviewing the notion of hegemony and then explain how it is relevant to studying the ideological effects of the new public health.

\section{HEGEMONY}

The concept of hegemony originates from the works of Antonio Gramsci (1971), and explains how the dominance of one group emerges in society through the acquisition of compliance from the general population. Such acquiescence is based on broader cultural and ideological currents that are accepted and taken for granted by the populace (Gramsci, 1971; Williams, 1977). Consequently, social control is maintained through the 'voluntary' acceptance of the dominant worldview (reflecting specific values, ideas and experiences) rather than through the overtly coercive measures of the state and industry. While all members of society may be implicated in and participate in the hegemonic structure, there are significant differences in the cultural production of hegemony between classes, which result from 
disparities in the acquisition of influence, such as economic and political authority. This power differential results in the universalization and naturalization of those values and ideas held by the dominant class; that is, an ideology that is necessary for the reproduction and perpetuation of the capitalist system as a whole.

Gramsci emphasizes the role of the intellectual in organizing and acquiring the 'consent' of the masses in support of the dominant class through the prestige of their expert positions (Gramsci, 1971, p. 12). The prevailing ideologies that maintain the positioning of the dominant class are further sustained through the institutionalization of dominant values and ideas. Within state structures, the role of professionals and intellectuals (all 'experts' who acquire their status through various forms of educational - and other - capital accumulation) are fundamental to the 'establishment of universally recognized definitions of social reality' (Johnson, 1995, p. 14). The construction of problems, norms and solutions by the expert within the institutionalized context of state governance functions as a system of legitimation for the governing process.

The 'spontaneous consent' that is conferred by the general population is a crucial component of hegemony and is ultimately a product of bourgeoisie stature in society. This compliance is supported by state apparatuses; however, the concept implies an unthinking acceptance of the social order, regardless of the dominated state of those complying with rules and practices. In rare cases, when spontaneous consent is not achieved, coercive means of discipline will be implemented to eliminate the threat of opposition or resistance; however, in such situations, Gramsci asserts that the force exercised is represented as supporting the needs and interests of the majority. Accordingly, Gramsci refers to the 'crisis of hegemony' when describing those situations where the consent is threatened. For instance, this occurs when classes abandon their political parties in favour of a growth in the power and autonomy of civil society accompanied by the consequent decline in state power.

The concept of hegemony has been used in many areas of academic study, such as cultural studies (e.g. Wood, 1998), literary studies (e.g. Williams, 1977) and international politics (e.g. Chomsky, 2003); however, it has been neglected in enquiries focusing on public health or medicine. Thus, we assert that hegemony is a valuable concept that provides an important entry point to the study of the state institution of public health during an infectious disease outbreak. This is because a disease outbreak situation may serve as a catalyst for the re-examination of how public health functions within a society, thus serving as a potential triggering point for a hegemonic crisis. 


\section{THE NEW PUBLIC HEALTH HEGEMONY}

Petersen and Lupton (1996) write about the emergence of the 'new public health' and contrast that with the 'old public health'. Whereas the latter focused more on the environment and public hygiene and was closely connected to the sanitation movement's attempts to improve living conditions to restrict the spread of disease, the new public health does not focus on social and physical structures but rather emphasizes the individual's responsibility for being a 'healthy citizen'. From this perspective, an individual is implicitly measured against standards that establish compliance with behaviours and affiliation with environments that are consonant with the public health prescription of a 'healthy lifestyle.' For example, such an implicit thrust can be found in public health dialogues that advise the public about behaviours pertaining to the use/avoidance of tobacco, alcohol, engagement in proper exercise, monitoring one's diet and so forth - all of which are based on an assumption of self-surveillance among members of the population. In this context, Petersen and Lupton (1996) assert that the 'healthy body' is increasingly being used as a means of indicating one's moral worth, where the individual can publicly express the virtues of self-control and discipline and simultaneously one's conformation to the criteria of being 'normal', healthy individuals - as prescribed by the dictates of the new public health.

The new public health's emphasis on the 'healthy citizen' and the individual's responsibility in maintaining of good health complements neoliberal ideologies and policies that enforce the reduction of state programmes and the dominance of private markets and interests in all realms of social life. These values inherent to neoliberalism and the new public health emphasize individual responsibility and subsequently minimize the obligations of collective institutions of civil society in matters of public health. As a result, processes such as the racialization and feminization of disease are obscured through a narrow focus on normative discourses on health and a profound belief in the myth that existing markets and structures are subject to fairness and equality. Such narrow understandings of health and the widespread conviction that egalitarian values are represented in structures relating to the health of the population assist in the maintenance of the 'spontaneous consent' of the general population, where most citizens unquestionably accept the governance of health within society.

In addition, instead of being democratically defined, measures of health and health intervention programmes or procedures are identified primarily by public health 'experts'. This conceptualization of the new public health is informed by Michel Foucault's work on power, which views the state as 
governing through laws, language and knowledge in its definition of normalcy for the subjects of the state, where regulation is not directly performed by the state, but where individuals are called upon to regulate themselves (Petersen and Lupton, 1996; Armstrong, 1995a). In public health, experts assist in the process of self-governance, by offering an enlightened perspective in health-promoting advice and endorsing social institutions that promote 'healthy' lifestyles and choices. Individuals are expected to engage in self-regulation based on these directives; however, in this process, there is insufficient recognition of the potential for differences in ability to conform to directives, the social cost of participation and the consequences experienced for those who do not participate. The role of experts is essential to the new public health, because it represents the dominance and pervasiveness of scientific knowledge in the rational-legal governance of the body in Western societies. In this vein, Brown and Duncan (2002) note 'the discursive practices of the 'new' public health [represent] new forms of governance, regulations and social control... [that] serves to legitimize ideologies and social practices by making statements about how individuals should conduct their lives' (p. 364).

The new public health structure is connected to Gramsci's concept of hegemony in its propagation of the interests of dominant groups through tacit means of domination and social control, accomplished through the general compliance within the population, which in the case of the SARS outbreak was accompanied by the 'intermittent threat' of discipline. Furthermore, novel forms of governance that are dominant in the current era are vividly demonstrated during an infectious disease outbreak such as SARS, as the urgency of such situations allow for, and require, less tacit forms of social control, such as strategies of surveillance.

\section{SURVEILLANCE}

A discussion of surveillance within public health can be informed by Foucault's (1977) exploration into the transformation of discipline toward more rationalized forms of punishment within modern society. Foucault documents the shift to modern manifestations of power, where the object of discipline transfers from the site of the individual body to the entire population. This is accomplished through more insidious systems of governance, which focus on surveillance strategies that continuously monitor populations (referred to as 'disciplinary techno$\log [i e s]$ ') and simultaneously induce self-regulation by the individual (Dreyfus and Rabinow, 1982, p. 188). 
Foucault's analysis of power is characterized by the normalization of the obedient subject, one who habitually complies, accompanied by the construction and control of deviance (Wuthnow et al., 1984; Johnson, 1995). In this highly complex structuring of power, individuals are governed by institutionalized forms of knowledge and technology, which function to perpetuate and legitimize their command over the docile body. This control is embodied in a system of expertise, epitomized by emerging disciplines of professional understanding, such as medicine and psychiatry, where power structures are reinforced and sustained through categories of knowledge (Wuthnow et al., 1984). In this context, the construction of a society of subjects focused on self-surveillance allows for an increase in the efficiency and anonymity of surveillance over the entire body of the population. Such a power structure ultimately results in the exclusion and marginalization of those individuals and groups that are labelled as deviant due to their failure to conform to prescribed behaviours and norms.

The concept of an increasing and tacitly governed citizenship has regularly been applied to the field of health. Armstrong (1995a, b) discusses the rise in 'surveillance medicine', which has adjusted its focus away from the 'unhealthy' body toward the monitoring of 'healthy' populations, where the responsibility for monitoring health is transferred to the individual. In this sense, health has become fundamental to the governance of populations in Western societies (Brown and Duncan, 2002). The role of 'experts' is essential within this system of power, as it is their responsibility to provide the directives, informed by privileged knowledge, through which the individual can self-monitor. A system of health experts under the new public health hegemony contribute to the compilation of 'technical' information (which is represented as being politically neutral) and consequently encourage the naturalization of continual self-monitoring in accordance with prescribed social norms. Such expertise is especially significant in cases of infectious disease outbreaks, where information is necessary in the preservation of the social order and the aversion of a 'crisis in hegemony.'

Health surveillance involves the tracking of health events or health determinants through the continuous collection of data by 'experts'. Data are analysed, interpreted and then used to make decisions about issuing advisories, alerts or warning (Naylor et al., 2003). The SARS outbreak was accompanied by an extensive reliance on epidemiological techniques used by public health for the surveillance of the population in order to track the virus. Strategies used by public health units in their attempts to control the SARS outbreak included surveillance, contact tracing, isolation and quarantine, and travel restrictions (Gostin et al., 2003). Surveillance networks relevant to the 
SARS outbreak in Toronto include the provincial Reportable Disease Information System (RDIS), the integrated Public Health Information System and the Global Public Health Intelligence Network (GPHIN) (D’Cunha, 2004; Basrur et al., 2004). These surveillance devices are representative of the disciplinary technology discussed by Foucault in their responsibility for the maintenance of the existing social order and minimizing disruption to the neoliberal capitalist economy. Furthermore, such surveillance systems function to reaffirm the value and power instilled in the realm of medical knowledge and public health expertise within society.

According to Dr Sheela Basrur, the Toronto Medical Officer of Health at the time of the outbreak, '[t]he main roles of Toronto Public Health (TPH) were case investigation and management, identification and quarantine of contacts, disease surveillance and reporting, health risk assessment and infection control advice to health institutions and other community settings' (Basrur et al., 2004, p. 22). Surveillance techniques intended to monitor SARS-invaded all social spaces, including airports, religious institutions, hospitals, schools and private homes (Naylor et al., 2003; Basrur et al., 2004). Despite extensive acknowledgement of airport surveillance as ineffectual, the practice continued throughout the SARS outbreak. The Naylor et al. (2003) report refers to one perspective speculating that airport screening in SARS surveillance actually functioned to enhance business confidence (p. 206), suggesting that this specific surveillance mechanism existed more as a result of business interests in the wake of SARS, than to protect the health of the population, thus serving to maintain the hegemonic dominance of capitalist interests.

The continual observation of such spaces throughout the outbreak was complemented by the expectation that citizens would partake in personal monitoring of themselves as potential SARS cases. Along with pervasive surveillance techniques implemented by the state, individuals were instructed (through the use of the media) by public health officials to monitor themselves for symptoms of SARS and identify themselves as at-risk for the virus through criteria such as, their exposure to other SARS patients and travel patterns. In general, compliance to directives was widespread and there were regular reports of city residents claiming abnormal health states that may have represented possible SARS cases (Basrur et al., 2004; Naylor et al., 2003). The tendency toward self-surveillance throughout the SARS outbreak is representative of a form of spontaneous consent under the new public health hegemony. This spontaneous consent is emblematic of an unreflexive acceptance of the role of scientific authority in everyday lives, where scientific knowledge has increasingly developed to dictate 'ideal' practices and lifestyle. 
In Toronto, approximately 23,300 people were documented as contacts of SARS cases and just less than half of these were placed in quarantine (Basrur et al., 2004). Imperative to these processes was the cooperation and compliance of Toronto residents with those directives outlined by public health officials. In the event that these systems of surveillance failed to induce self-monitoring and identification by individuals, Section 22 of Ontario's Health Promotion and Protection Act requires mandatory disease reporting and control, empowering the province to order involuntary isolation if necessary (D'Cunha, 2004; Speakman et al., 2003). In Toronto, 27 isolation orders were issued for individuals who failed to comply with quarantine directives (Basrur et al., 2004). While isolation orders may have been temporarily harmful to the Toronto economy, by weakening the labour force, such measures represent the sacrifice of short-term circumstances in favour of long-term success within the neoliberal economy. That is, short-term economic losses were considered minimal in comparison to the potential damage caused by an uncontained epidemic. In addition, the flexibility and impermanence of the workforce under neoliberal agendas means that the removal of a small percentage of workers from their jobs due to health problems is fairly inconsequential given their potential to be replaced by other healthy workers.

\section{RISK}

Accompanying the increasing importance of surveillance in the governance of modern populations is the individualization of responsibility for 'personal' health. Fundamental to this specific form of social control is the use of the discourse of risk in providing directives on maintaining healthy normative behaviours and lifestyles (Crawford, 1977). That is, surveillance medicine transforms signs, symptoms and disease into general categories represented as 'risk factors', which rather than representing the actual occurrence of disease indicate the potential for disease in the future (Armstrong, 1995b). Armstrong (1995b) asserts that the subject of surveillance medicine is, in fact, the 'risky self', where 'surveillance machinery deployed throughout a population to monitor precarious normality delineates a new temporalised risk identity.' (p. 403)

Mary Douglas' (1966) analyses of the systematic ordering and classification of matter where the existence of everyday objects such as dirt can only be understood when examined within a symbolic system of purity, can contribute to a discussion on the construction of risk in society. The relativity of such a system is emphasized in this analysis where that which is perceived 
of as 'dirty' can only be defined in relation to that which is 'clean'. The analysis of the creation of socially defined boundaries that distinguish between 'dirty' and 'clean' spaces or people is relevant to discussions of public health, where attempts to identify healthy versus unhealthy populations dominate discourses relating to risk. Inherent in conceptualizations of 'risk groups,' relevant to health, is the distinction between the tainted and the pure, and by extension results in the 'othering' of groups based on (potential) ill-health statuses.

The term 'risk' has come to dominate public health dialogues with the identification of 'risky behaviours', 'sources of risk' and 'risk groups' that relate to health. As mentioned, the surveillance of populations for explicit 'risk factors' affecting health indicates a shift in conceptualizations of illness as a phenomenon that transpires within the individual body to one that inhabits a novel 'extracorporal space' (Armstrong, 1995b, p. 395). One outcome of this adjustment has historically been (and arguably, continues to be) that disease is attributed to specific populations and related spaces within society. The epidemiological understanding of 'risk groups' as neutral and empirical descriptions can inadvertently/intentionally result in the identification of these risk groups as responsible for the spread of disease. The presentation of 'risk groups' as arising from objective value-free criteria leads to the treatment of individuals as consumers who have unrestricted choice in their exposure to risks. Furthermore, the role of discrimination and marginalization within the construction of dominant understandings of risk groups and the reality that these risk groups often overlap with social groups is frequently overlooked. For example, the history of conflating AIDS risk groups with the gay population in the U.S. has not only reinforced existing attitudes of discrimination, but has also led to inadequate understandings of the disease (Fee and Krieger, 1993). Simultaneously, the representation of disease in populations based on potential 'risk groups' versus social groupings, based on race, class or gender, effectively functions to depoliticize potentially contentious understandings and realities of health experiences.

The use of 'risk' in public health can be interpreted as a mechanism for the construction of deviance and marginality and in turn as a tool for social control. Within the conceptualization of risk is the implicit process of differentiation, whereby there is an 'othering' of populations associated with the risk-taking behaviour or source. The distinction between an 'at-risk' versus 'safe' population in public health programmes can function to (further) marginalize groups associated with risk-taking behaviours (Fischer and Poland, 1998). The call to increase the efficiency of surveillance and diagnostic systems reflects a constructed need to control populations to prevent the further spread of disease. The creation of categories of risk 
through the management of risks in public health strategies can be interpreted as serving as a technique for governance and consequently perpetuates a form of governance that is implemented through mechanisms of exclusion and social control (Fischer and Poland, 1998). Such control of spaces and people through their identification as at-risk is vital to the maintenance of hegemony, as the fragility of spontaneous consent is accentuated by displays of 'deviance' within society. Thus, the divergence from the standard norms must be labelled and managed in order to indicate the depravity and difference of dissent or non-compliance by people within social spaces.

The unknown was prevalent during much of the SARS crisis, demonstrated by a constant defining and redefining of borders through changing knowledge of the disease and disease transmission (McGillis Hall et al., 2003; Affonso et al, 2004). For example, transforming understanding regarding the effectiveness of face masks in preventing transmission resulted in changes in the use of this equipment both in the hospitals and the community (Affonso et al, 2004). In addition, the federal and Ontario governments provided dissimilar definitions of what constituted probable and suspected SARS cases and ' $[\mathrm{b}]$ oth jurisdictions revised their definitions intermittently' (Naylor et al., 2003, p. 40) illustrating the shifting boundaries in knowledge of the disease. As a result, people were constantly adjusting their responses and perceptions to identify potential threats or risks. The anxiety surrounding, and inability to deal with, uncertainty experienced within the SARS outbreak, coupled with the weak and confused public health infrastructure, meant that much of the SARS experience was characterized by the struggle to identify exact clinical definitions of SARS and set procedures necessary for the control of SARS (Naylor et al., 2003).

This was exacerbated by the criticism made towards public health officials regarding the number of 'voices' involved in risk communication, where there appeared to be greater public concern stemming from the fact that there were a number of different people speaking authoritatively about SARS, thus frequently providing the public with conflicting information (Naylor et al., 2003; Affonso et al., 2004). Furthermore, the reliance on quarantine measures to separate the healthy from the unhealthy (or more accurately, the potentially unhealthy), during the outbreak, implicitly distinguished between 'clean' and 'dirty' spaces and citizens that in turn promoted the myth of purification regarding people and spaces. As will be discussed, such practices of differentiation have the potential to be severely detrimental to those groups associated with disease due to constructed 'risk factors' by reinforcing processes such as the racialization of disease and the pathologization of places and communities (Bashford, 2002; Craddock, 1995). 
Furthermore, the preoccupation of health officials and workers to provide an exact definition for the categorization of SARS patients can be attributed to society's inability to manage situations where boundaries are not explicitly distinct. It also demonstrates a need to eliminate such ambiguities in order to maintain control over situations such as the SARS outbreak. In the case of SARS, risk became a collectively (but not equally) experienced phenomenon. At the same time, the individual in Toronto was responsible for monitoring personal symptoms in the quest to maintain of a healthy populace. Such mechanisms are powerful at maintaining of a generally compliant population, primarily through the instillation of fear of contracting some unknown disease. Simultaneously, risk discourses perpetuate social exclusion through the identification of groups with disease and consequently the construction of the 'other' in space.

While the increased risk of infection with SARS may not be connected to a specific behaviour, there are practices that are interpreted as increasing or lowering one's chances of acquiring the infection. This was exemplified during SARS by the intensive monitoring of airports, hospitals, religious gatherings and schools in order to isolate people with symptoms of infection, and spaces associated with these behaviours (Naylor et al., 2003; Basrur et al., 2004). This monitoring results in the differentiation between people based on specific clinical definitions that distinguish between SARS (probable, suspected, etc) and non-SARS cases, which could in turn lead to the isolation, and subsequent exclusion, of those fitting the SARS 'profile' or those who were considered more 'at-risk' of acquiring the virus (as was seen by the stigmatization of many hospital workers in Toronto). Hospital workers and their families reported the experience of severe social exclusion throughout SARS. Examples include the description of members of the public blatantly avoiding the homes of nurses, nurses who had difficulty finding daycare services for their children and taxi drivers refusing to transport nurses to their places of employment (McGillis Hall et al., 2003).

Not surprisingly, it is the populations associated with risks, that most often represent previously marginalized groups who have diminutive power over the definitions of 'risk groups'. These populations then responsible for reaffirm their constructed deviance within society. For example, there has been a long history of associating immigrants (perceived of as 'foreign' like the disease for which they are deemed responsible) with disease in Western societies. Craddock (1995) documents the 'metonymy between place and disease' in 19th century San Francisco, where the Chinese community and Chinatown were explicitly scapegoated for the progression of smallpox within the city (p. 61). 
While SARS was not explicitly linked to a specific population by public health, it was overtly and tacitly associated with the Chinese community and spatially with Chinatown in Toronto. The identification of sites of 'risk' (in this case of SARS, these sites included China and other areas in Asia) often results in spaces, and consequently people, being associated with disease. Although in Canada the general trend has been that overtly racist stereotypes have been replaced by new, more covert racialized articulations and attitudes (Hier and Greenberg, 2002), extreme circumstances such as the outbreak of infectious diseases may serve as the catalyst for the return of more overt forms of racism. Thus, such situations where the infected or exposed to SARS are separated from the healthy can potentially result in public health functioning as a 'subterfuge for discrimination' (Gostin et al., 2003, p. 3233).

It was evident that racism was experienced by many Chinese Canadians in Toronto during the SARS outbreak. For example, there were reports from Chinese-Canadians that many in their community faced daily exposure to racist attitudes, which ranged from people refusing to sit next to them on the public transit system to overt expressions of blame for the SARS outbreak (Leung and Guan, 2004). Several Asian-Canadian tenants were told to move out by their landlords; a government official visiting a nursing home caring primarily for Chinese-Canadian seniors insisted on wearing a mask during her entire visit to do routine testing and commented to the nursing home staff that she only wore the mask at the particular institution; domestic workers from the Philipino-Canadian community were laid off; while staff from the Canadian Immigration and Refugee board insisted on wearing masks only during those hearings involving those of Chinese descent (this practice was dropped after a formal complaint was lodged by Asian Canadian Labour Alliance). Furthermore, the Chinese Council of Canadians noted that they had received several racially-based voice messages that singled out the Chinese community for the outbreak (Sorensen, 2003).

The call to increase the efficiency of surveillance and diagnostic systems reflects a socially constructed need to control populations in order to prevent the further spread of disease. The creation of categories of risk through the management of risks in public health strategies can be interpreted as perpetuating a form of governance that is implemented through mechanisms of exclusion and social control (Fischer and Poland, 1998). The SARS experience was monopolized by the practices of risk assessment and management that involved an expansive system of surveillance involving epidemiological techniques attempting to define, map and 'efficiently' control the virus. This, in turn, extends to the control of people and places/spaces.

In the case of SARS the 'risk' was identified by experts within public health and the healthcare profession, who were essentially responsible for the 
construction of categories and boundaries of what constitutes and what is excluded through the identification of 'risk.' Such constructions are generally labelled as subject to individual choice but are frequently affected by broader issues, such as economic positioning, often overlooked within public health dialogues.

\section{MORALITY}

Another component relating to the new public health hegemony is the underlying ideological element of public health as a 'moral enterprise'. This is founded on an understanding of public health as an essentially moral enterprise that provides directives on the way we should live our lives both individually and collectively (Petersen and Lupton, 1996). Furthermore, a discussion of the role of risk discourses during the SARS outbreak connects to this section by addressing the more tacit element of morality within the public health system. From the very definition of risk follows the obligation to minimize risks and purify people and places, and by extension the distinction between 'clean' versus 'dirty' or 'good' versus 'bad'. Several Canadian researchers assert that public health campaigns that target activities and conditions such as smoking and obesity reflect the underlying social values that certain behaviours are harmful to the morality of the population (Robertson, 1998; Fischer and Poland, 1998; Bercovitz, 2000). Implicit in the construction of norms that reinforce 'healthy' behaviours is the distinction between acceptable and unacceptable behaviours/environments, and consequently people and places.

The power disparities inherent in the construction of norms and guidelines with respect to health risks are habitually overlooked within discussions of health (Poland, 2000). That is, the social positioning of those experts providing directives, and the consequent potential for the reproduction of inequalities based on characteristics such as class, 'race' and gender, is a neglected topic within public health discussions. In fact, the presentation of expertise as a neutral endowment allows for an effective means of fulfilling the interests of the dominant class, while dissociating expert decisions from political/public contention. In short, the experts who define problems, whether they relate to health, the environment, economic issues, and so forth, are conveyors of a political discourse that substantiates their official privilege through their alleged neutrality. This is very much a class issue, as it is primarily those individuals with higher levels of educational, social and cultural capital who hold occupational positions that dictate social norms and impose needs (Bourdieu, 1984; Craddock, 1995; Johnson, 1995). 
Fundamental to this reproduction of inequality is the reality that the construction of legitimacy monopolized by one privileged group results in dominated groups who are less able to conform to such norms, having no role in the construction or implementation of these standards. According to Crawford (1977), the process whereby individuals are deemed responsible for minimizing their risk of contracting disease or other health implications encourages a form of social control where by vulnerability to risk reveals a psychological or moral shortcoming in the individual. Consequently, the importance of structural causes of inequality and disease is routinely overlooked in a world where the view of the individual as a free agent is widely held. This produces a 'victim-blaming' effect where the individual's failure to conform to normative health discourses is the result of an inherent moral shortcoming in the person. Such an outlook is a powerful tool in the legitimation of structural causes of inequality, where differences are rationalized through emphases on inconsistencies between 'personal' lifestyle decisions as if they were individual consumer choices (Poland, 2000; Musheno, 1997).

In the case of SARS in Toronto, the discourse of morality involved the promotion of individual sacrifice for the collective good of the population. The favouring of public versus private interests, in this case, diverges from the more dominant tendency to value individual freedoms and rights. This focus on the collective good could be at least partially attributed to the potential for the universality of the SARS threat (as well as the political context of the situation). That is, during the outbreak there was the general representation that one could be infected with SARS, regardless of characteristics such as, class, geography and sexual behaviour, instead of being specific to one particular (usually marginalized) group. It is important to note, that while the actual experience of stigmatization resulting from SARS was unequally endured by specific social groups, such as Asian Canadian communities and healthcare workers (representing a disproportionate number of female workers), public health dialogues on the infectious disease continually neglected discussions of race and gender with respect to the effects of SARS in Toronto. While SARS was partially represented as a universal threat, the emphasis on individual responsibility for recognizing risks and protecting the remaining population encouraged the neglect of potential for differences in ability or inclination to conform to safety protocol, as demonstrated by the trepidation experienced when individuals failed to conform to 'official' regulations. For example, anxiety was expressed when three hospitalized psychiatric patients who were quarantined as suspected SARS cases refused/were unable to conform to quarantine regulations (Naylor et al., 2003). 
120

The moral discourse emphasizing individual sacrifice was perpetuated in all environments throughout the SARS outbreak. Within the hospitals, there were a number of situations where health workers were criticized for minor breaches in safety procedures (Naylor et al., 2003). The emphasis on the individual's responsibility to minimize others' exposure to risk throughout the SARS outbreak disregarded the reality that abilities and inclinations to control behaviours affecting exposures to risk were not homogeneous throughout the entire population. In this case, the individual was responsible for self-surveillance and identifying one's self as a 'risk' to the rest of the population and consequently adhering to quarantine measures and other directives identified by public health officials. This was encouraged by a number of surveillance measures including voluntary quarantine measures, and involved a clear stigmatization of those who were unwilling or unable to adhere to the safety protocol. The necessity for compliance to identified protocol was consistently emphasized throughout the SARS outbreak, with the media announcing failures to comply, public health workers regularly calling the homes of those in quarantine (sometimes once or twice per day) to ensure compliance, and in some cases the assignment of court directives forcing compliance (Basrur et al., 2004). Those who were unwilling to comply were at times openly reprimanded by public health officials. Members of one Toronto high school that was closed due to the mass quarantine of 1,500 students and staff into their homes faced harsh warnings from Ontario's commissioner of public health were they not to follow quarantine regulations, as he threatened to impose fines or lock violators in hospitals with guards at the door (Gostin et al., 2003).

\section{SECURITY}

The political climate in North America following the events of September 11, 2001 have given rise to the legitimation of heightened surveillance and scrutiny in the U.S. and Canada under the rubric of 'national security'. As a result, there has been a pervasiveness of national security discourses within the recesses of everyday activity. This has been especially the case in public health arenas, where political paranoia regarding security threats such as bioterrorism has remained a thoroughly contemplated topic. Correspondingly, there has been an extraordinarily narrow and specific conceptualization of who is considered a threat to national security; a construction of danger that is an explicit process of differentiation between 'us' and 'them', the 'them' a continuous representation of a specific 'racial profile', which clearly serves as a mechanism to justify specific highly contested/problematic political 'interventions' by U.S. leaders. 
Historically, there has been a tendency to conflate 'race' and migration issues with public health concerns, which has provided some level of legitimacy to racist ideologies through the support of epidemiological or medical observation (Markel and Stern, 1999, 2002; Bashford, 2002). Indeed, this is exemplified by recent U.S. immigration policies, where the Clinton administration restricted incoming migrants with HIV, providing the rationale that these people would be a 'drain' on the healthcare system (Markel and Stern, 2002). In the post-September 11 environment, there appears to be a permissiveness surrounding forms of social control that promote racism and exclusion. In part, this permissiveness stems from pervasive representations that perpetuate fear and uncertainty in the everyday lives of individuals. Unfortunately, there is great potential for the exploitation of this 'climate of fear' by state institutions, such as public health, for the advancement of specific (conservative) political agendas. Public health security is increasingly a central concern within the new public health hegemony, and represents a seemingly neutral approach to existing health threats. In actuality, government concerns for public health security closely parallel the need for the maintenance of the neoliberal capitalist system that commands an unregulated movement of goods and resources in an effort to maximize profits and efficiency. The threat of SARS to such a system is unmistakable, with international concern surrounding the danger of exposure to Canadians and Canadian goods developing throughout the outbreak.

It is possible to parallel the heightened security and racial profiling in current climates with the scapegoating and racialization of disease experienced in Toronto during the SARS outbreak. The perception of immigrants (from specific origins) as threats to public health undoubtedly served as a backdrop to, and subtly influenced, the response to ChineseCanadians during the SARS crisis. Hier and Greenberg (2002) note that although expressions of explicitly racist stereotypes appear to have dissipated in Canada, they have in fact re-appeared in a variety of new racialized discursive articulations that do not make reference to explicit biological or genetic terms. These articulations are covert in nature and include such stereotypes as 'unneighbourly houses', 'unusual aesthetic values', 'substandard social integration', and 'criminality' (examples given in: Li, 1994, 1998; Tator et al., 1997; Henry and Tator, 1994; Ma and Hildebrandt, 1993). Extreme situations such as disease outbreaks may, however, serve as the impetus for the return of more overt forms of racism.

In this light, one outcome of the specific approach to public health discussed in this paper is the clear stigmatization and exclusion of communities and groups within Toronto. The Chinese Canadian National Council compiled as impact report entitled Yellow Peril Revisited: Impact of 
SARS on the Chinese and Southeast Asian Canadian Communities which details the personal and general experiences of discrimination by community members throughout the SARS outbreak (Leung and Guan, 2004). Furthermore, frontline health workers, especially the nursing profession, experienced a great deal of prejudice due to their perceived proximity to the disease.

\section{CONCLUSION}

While analyses of constructions of the healthy citizen are fundamental to critiques of the new public health, the healthy citizen is also undoubtedly essential within capitalist systems of production. Simultaneously, there is arguably an inherent contradiction within capitalism, in its reproduction of unhealthy citizens, characterizing inequality in health outcomes within society (Navarro, 1986; Navarro and Berman, 1977). The objective of this paper has been to indicate the potential for the reproduction of inequality and marginality (conditions that are harmful to the health of the general population) through the naturalization of procedures by the state institutions of public health, which demonstrates a specific example of hegemony. Furthermore, Toronto's public health response to SARS provides a specific example of the perpetuation of inequality within everyday social practices.

This has been demonstrated through an analysis of the implementation of rigid codes of behaviour outlined by the public health expert, the identification and surveillance of risk groups and the role of science as the primary authority within public health. As well, the persistence of rhetoric perpetuating 'security concerns' and the role of public health workers as moral agents, further support the public health hegemony. These components of public health function as powerful tools for social control and mechanisms of exclusion, and essentially reproduce existing hierarchies. In addition, we have demonstrated the intricate relationship between force and consent characterizing hegemony through the description of public health practices, such as surveillance technologies, which were vital to maintain social control during the SARS outbreak.

Finally, an important feature of hegemony as indicated by Williams (1977) is that 'while by definition it is always dominant, it is never either total or exclusive. At any time, forms of alternative or directly oppositional politics and culture exist as significant elements in the society' (p. 113). It is our assertion that the increasing acceptance of surveillance and reliance on surveillance mechanisms within public health, evident in the numerous 
reports and recommendations published following the SARS outbreak, may result in a diversion of funds and energy away from other essential areas of public health that promote the objective of social justice; those areas that support the 'oppositional politics' challenging dominant hegemonic structures.

\section{ABOUT THE AUTHORS}

Sarah Sanford is currently a graduate student in the Masters of Environmental Studies Program at York University. Her research involves the development and application of social theory to issues pertaining to the relationship between environment and health.

S. Harris Ali is an assistant professor in the Faculty of Environmental Studies at York University. His areas of research interest include: environmental sociology, risk management, and the analysis of environmental health disasters, such as chemical contamination incidents and disease outbreaks.

\section{REFERENCES}

Affonso DD, Andrews GJ, Jeffs L (2004). The urban geography of SARS: paradoxes and dilemmas in Toronto's health care. Journal of Advanced Nursing 45: 568-578.

Armstrong D (1995a). Public Health Spaces and the Fabrication of Identity. Sociology 27: 393-410.

Armstrong D (1995b). The rise of surveillance medicine. Sociology of Health and Illness 17: 393-404.

Bashford A (2002). At the border: contagion, immigration, nation. Australian Historical Studies 120: 344-356.

Basrur SV, Yaffe B, Henry B (2004). SARS: a local public health perspective. Canadian Journal of Public Health 95: 22-24.

Bercovitz KL (2000). A critical analysis of Canada's 'active living': science or politics? Critical Public Health 10: 19-39.

Bourdieu P (1984). Distinction: A Social Critique of the Judgement of Taste. Harvard University Press: Cambridge. 613pp.

Brown T, Duncan C (2002). Placing geographies of public health. AREA 34: 361-369.

Campbell A (2004). The SARS Commission Interim Report: SARS and Public Health in Ontario (Commissioned by the Ontario Ministry of Health and Long-Term Care). 222pp.

Chomsky N (2003). Hegemony or Survival: America's Quest for Global Dominance. Metropolitan Books: NY. 278pp.

Craddock S (1995). Sewers and scapegoats: spatial metaphors of smallpox in nineteenth century San Francisco. Social Science \& Medicine 41: 957-968.

Crawford R (1977). You are dangerous to your health: the ideology and politics of victim blaming. International Journal of Health Services 7: 663-680.

D'Cunha C (2004). SARS: lessons learned from a provincial perspective. Canadian Journal of Public Health 95: 25-26.

Douglas M (1966). Purity and Danger: An Analysis of Concepts of Pollution and Taboo. Praeger: New York. 188pp.

Dreyfus HL, Rabinow P (1982). Michel Foucault: Beyond Structuralism and Hermeneutics. The University of Chicago Press: Chicago. 271pp.

Fee E, Krieger N (1993). Public health then and now - understanding AIDS: historical interpretations and the limits of biomedical individualism. American Journal of Public Health 83: 1477-1486.

Fischer B, Poland B (1998). Exclusion, 'risk', and social control - reflections on community Policing and public health. Geoforum 29: 187-197. 
Foucault M. (1977). Discipline and Punish: The Birth of the Prison. Pantheon Books: New York. 333pp.

Gostin LO, Bayer R, Fairchild AL (2003). Ethical and legal challenges posed by severe acute respiratory syndrome. JAMA 290: 3229-3237.

Gramsci A (1971). Selections from the Prison Notebooks. International Publishers: New York. 483pp.

Henry F, Tator C (1994). The ideology of racism - democratic racism. Canadian Ethnic Studies 26: 1-14.

Hier SP, Greenberg JL (2002). Constructing a discursive crisis: risk problematization and illegal Chinese in Canada. Ethnic and Racial Studies 25: 490-513.

Johnson T (1995). Governmentality and the institutionalization of expertise. In: Johnson T, Larkin J, Saks M (eds). Health Professions and the State in Europe. London: Routledge. pp. 7-24.

Leung C, Guan J (2004). Yellow Peril Revisited: Impact of SARS on the Chinese and Southeast Asian Canadian Communities. Chinese Canadian National Council: Toronto. 45pp.

Li P (1994). Unneighbourly houses or unwelcome Chinese: the social construction of race in the battle over 'Monster Homes' in Vancouver, Canada. International Journal of Comparative Race and Ethnic Studies 1, pp. 14-33.

Li PS (1998). The Chinese in Canada. Oxford University Press: Toronto. 190pp.

Ma J, Hildebrandt K (1993). Canadian press coverage of the ethnic Chinese community: a content analysis of the Toronto Star and Vancouver Sun. Canadian Journal of Communications 18: 479-496.

Markel H, Stern AM (1999). Which face? Whose nation?: immigration, public health, and the construction of America's ports and borders, 1891-1928. American Behavioral Scientist 42: 1314-1331.

Markel H, Stern AM (2002). The foreignness of germs: the persistent association of immigrants and disease in American society. The Milbank Quarterly 80: 757-788.

McGillis Hall L, Angus J, Peter E, O’Brien-Pallas L, Wynn F, Donner G (2003). Media Portrayal of Nurses' Perspectives and Concerns in the SARS Crisis in Toronto. Journal of Nursing Scholarship 35: $211-216$.

Musheno M (1997). Legal consciousness on the margins of society: struggles against stigmatization in the AIDS crisis. Identities 21: 101-122.

Navarro V (1986). Crisis, Health, and Medicine: A Social Critique. Tavistock Publications: New York. $281 \mathrm{pp}$.

Navarro V, Berman DM (eds) (1977). Health and Work under Capitalism: An International Perspective. Baywood Publishing Company, Inc.: New York. 311pp.

Naylor D, Basrur S, Bergeron MG, Brunham RC, Butler-Jones D, Dafoe G, Ferguson-Paré M, Lussing F, McGeer A, Neufeld KR, Plummer F (2003). Learning from SARS: renewal of public health in Canada. A Report of the National Advisory Committee on SARS and Public Health (Health Canada). 234pp.

Petersen A, Lupton D (1996). The New Public Health: Health and Self in the Age of Risk. Sage Publications: London. 208pp.

Poland BD (2000). The 'considerate' smoker in public space: the micro-politics and political economy of 'doing the right thing'. Health and Place 6: 1-14.

Robertson A (1998). Critical Reflections on the Politics of Need: Implications for Public Health. Social Science \& Medicine 47: 1419-1430.

Sorensen C (2003). Chinese Canadians feeling backlash. The Toronto Star. 4 April.

Speakman J, Gonzalez-Martin F, Perez T (2003). Quarantine in severe acute respiratory syndrome (SARS) and other emerging infectious diseases (The Public's Health and the Law in the 21st Century: Second Annual Partnership Conference on Public Health Law). Journal of Law, Medicine \& Ethics 31: S63-S67.

Tator C, Henry F, Mattis W (1997). Challenging Racism in the Arts: Case Studies of Controversy and Conflict. University of Toronto Press: Toronto. 293pp. 
Walker D, Keon W, Laupacis A, Low D, Moore K, Kitts J, Vincent L, Williams R (2003). For the Public's Health. Initial Report of the Ontario Expert Panel on SARS and Infectious Disease Control (Ontario Ministry of Health and Long-Term Care). 169pp.

Williams R (1977). Marxism and Literature. Oxford University Press: Oxford. 271pp.

Wood B (1998). Stuart Hall's cultural studies and the problem of hegemony. British Journal of Sociology 49: 399-424.

Wuthnow R, Hunter JD, Bergesen A, Kurzweil E (1984). Cultural Analysis: The Work of Peter L Berger, Mary Douglas, Michel Foucault and Jürgen Habermas. Routledge: London. 273pp. 